\title{
Influence of Weather Conditions on the Surface Morphology and Wetting Behaviour of Superhydrophobic Quaking Aspen Leaves
}

\author{
J. J. Victor, U. Erb ${ }^{*}$ \\ Department of Materials Science and Engineering, University of Toronto, Toronto, Canada. \\ Email: "erb@ecf.utoronto.ca
}

Received March 12 ${ }^{\text {th }}, 2013$; revised April 20, th 2013 ; accepted May 15 $5^{\text {th }}, 2013$

Copyright (C) 2013 J. J. Victor, U. Erb. This is an open access article distributed under the Creative Commons Attribution License, which permits unrestricted use, distribution, and reproduction in any medium, provided the original work is properly cited.

\begin{abstract}
The effects of different environmental conditions on the wetting properties and surface morphology of surperhydrophobic quaking aspen leaves harvested during the 2011 growth season are examined. During this particular season quaking aspen leaves were not able to retain their superhydrophobic properties and associated surface structure features as they have usually been able to do in other years. Representative scanning electron microscopy images and wetting property measurements of quaking aspen leaf surfaces harvested throughout this season are presented and discussed with the objective of linking weather induced environmental stresses that occurred in 2011 to the sudden and unusual reduction in non-wetting properties and drastic changes in leaf surface structure. Erosion and regeneration rates of leaf wax crystals and the impact that environmental factors can have on these are considered and used to explain the occurrence of these unexpected changes.
\end{abstract}

Keywords: Quaking Aspen Leaves; Superhydrophobic; Surface Structure; Wax Crystal Erosion/Regeneration; Weather Conditions

\section{Introduction}

Since the 1990's superhydrophobic and self-cleaning leaf surfaces have been studied extensively; the most popular and first to be thoroughly examined being the lotus leaf [1-5]. It has been shown that the extreme non-wetting properties of these leaves arise from a unique dual-scale surface structure consisting of micro-scale papillae covered with nano-scale wax crystals [3,6-8]. Superhydrophobic leaf structures, possessing these unique surface features, have been used as a biological blueprint in the structuring of a variety of materials, rendering their surfaces highly water-repellent [9-13]. One of the most recent examples is the mimicking of the quaking aspen (Populus tremuloides) leaf structure to make superhydrophobic polymer and metal surfaces [14]. Although there has been a considerable effort to characterize and mimic these leaf surfaces, less is known about the exact mechanism(s) for the formation of these surface features, and how they react to different external environmental stresses.

\footnotetext{
"Corresponding author.
}

Over the past five years, we have been monitoring and analyzing the surface structures and wetting properties of quaking aspen leaves. Normally, shortly after leaf emergence in the spring these leaves exhibit superhydrophobicity (water contact angle $>150^{\circ}$ ) that remains for the rest of their growth season, is maintained even after leaf abscission and is preserved in the dried state for many years thereafter [8]. However, this trend was not observed during the 2011 growth season. At some point during this particular season (second half of August) the non-wetting properties of the aspen leaves were suddenly lost. It has been previously shown that the wetting characteristics of hydrophobic and superhydrophobic leaves are strongly influenced by the competition between 1) the degradation of nano-scale wax crystals due to environmental factors and 2) the self-repairing ability of the leaves through wax crystal regeneration [15-19]. In an effort to understand this unusual loss of the superhydrophobic properties of aspen leaves observed in 2011, the focus of the current study was to establish a link between wax crystal loss/regeneration and environmental factors such as temperature, precipitation, wind and relative hu- 
midity.

\section{Sample Preparation and Characterization Methods}

All quaking aspen leaf samples were collected throughout the 2011 growing season (May 14-October 9) from the same tree located in a forest near Peterborough, Ontario $\left(44^{\circ} 11.43^{\prime} \mathrm{N} / 78^{\circ} 24.26^{\prime} \mathrm{W}\right.$ and $214 \mathrm{~m}$ altitude) and analyzed within 48 hours. To fully characterize a surface's wetting behaviour both dynamic and static wetting measurements are necessary. For the assessment of static wetting characteristics, the contact angles between water droplets and levelled leaf surfaces were measured, while for dynamic measurements the sample's tilt angle (relative to horizontal) to initiate water droplet roll-off was recorded. Wetting property measurements and scanning electron microscopy (SEM) were performed on 1 inch $\times$ 1 inch leaf sections that were cut and mounted using double sided tape on flat Plexiglas ${ }^{\mathrm{TM}}$ coupons with their adaxial sides facing up. For contact angle measurements, leaf samples were placed on a pre-levelled stage and aligned with a horizontally positioned digital camera (Nikon D3000) equipped with a macro lens (Nikon-AF-S Micro Nikkor $40 \mathrm{~mm}$ ) which was used to image no less than four $5 \mu \mathrm{l}$ water droplets on each aspen leaf surface. Water droplet images were subsequently analyzed using ImageJ's contact angle function [20]. Tilt angle measurements were carried out using a tilting stage and $25 \mu \mathrm{l}$ water droplets.

Electron microscopy was performed using a Hitachi SU-6600 environmental scanning electron microscope (ESEM) which requires no coatings for surface electrical conductivity. This allowed freshly harvested, uncoated leaf samples to be imaged directly. All samples were analyzed using an environmental secondary electron detector (ESED) at a pressure of $60 \mathrm{~Pa}$. Images were taken at a $45^{\circ}$ sample tilt to enhance surface topography and highlight structural features.

\section{Results}

Figures 1-5 display multiple SEM images at different magnifications of quaking aspen leaves collected on five different days during the 2011 summer growth season. SEM images of a quaking aspen leaf harvested on May 14, 2011 (just a few days after leaf emergence) are shown in Figure 1. This young leaf surface does not exhibit the typical superhydrophobic leaf surface structure consisting of micro-scale papillae and nano-scale wax crystals that are responsible for non-wetting properties $[7,8]$. Instead, the leaf shows multiple, randomly oriented folds in the cuticle and no nano-scale wax crystals are present on its surface (Figure 1). Additionally, this sur- face contains many small contamination particles, indicating that it does not possess superhydrophobic/selfcleaning properties. In fact, the average water contact and tilt angles for these early leaves were $102^{\circ} \pm 6^{\circ}$ and $26^{\circ}$, respectively.

Figure 2 displays SEM images of a quaking aspen leaf harvested on May 22, 2011. It is clearly visible that multiple morphological changes have occurred during this relatively short growth period of only 8 days. The cuticular folds of the samples harvested on May 14, 2011 have acted as precursors for the random array of microscale papillae displayed on surfaces collected on May 22, 2011. Moreover, the entire leaf surface is now covered by a dense layer of nano-scale wax crystals, both on and in between surface papillae. Due to the development of these surface features, the non-wetting properties of these leaves have augmented to an average water contact angle of $148^{\circ} \pm 5^{\circ}$ and a tilt angle less than $5^{\circ}$. Effectively, the growth of this dual scale structure has rendered the quaking aspen leaves superhydrophobic and self-cleaning: a

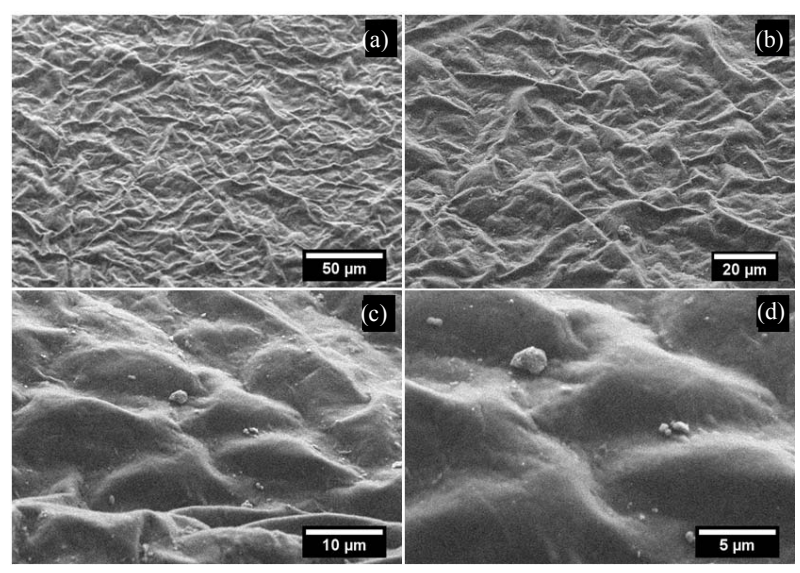

Figure 1. SEM images of the adaxial side of a quaking aspen leaf harvested on May 14, 2011.

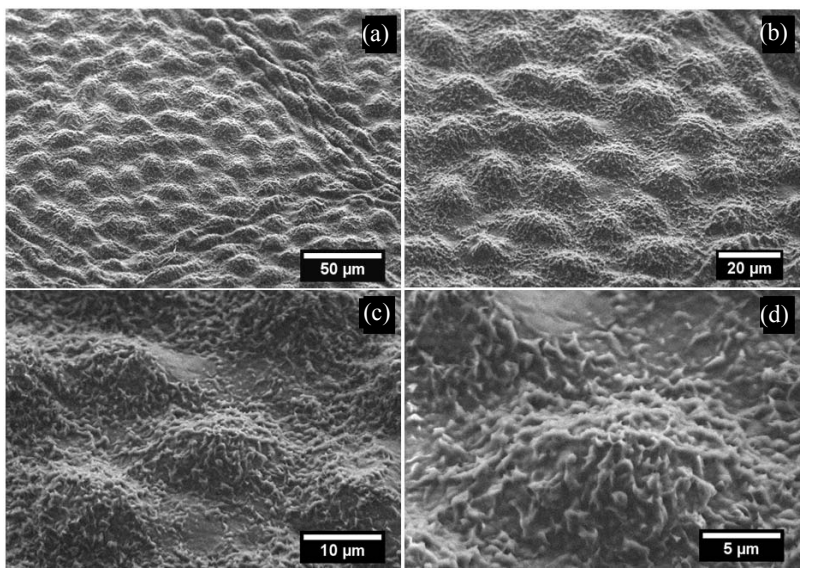

Figure 2. SEM images of the adaxial side of a quaking aspen leaf harvested on May 22, 2011. 


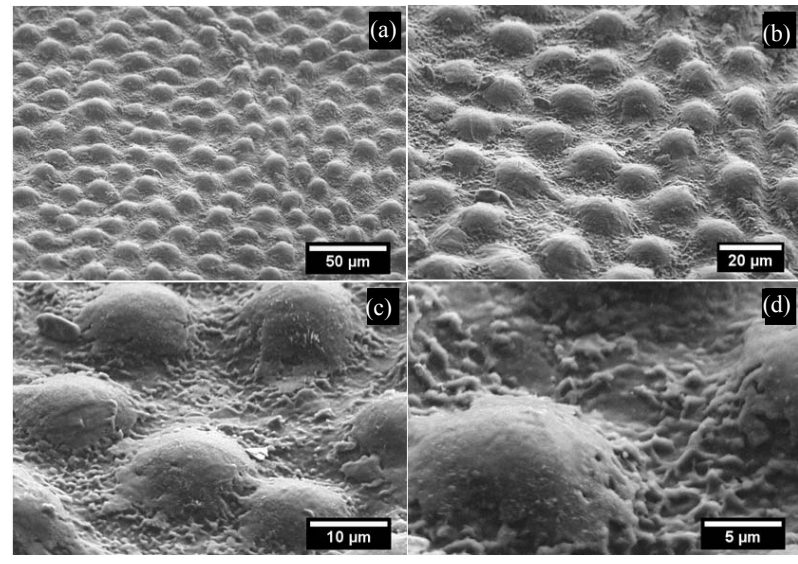

Figure 3. SEM images of the adaxial side of a quaking aspen leaf harvested on June 5, 2011.

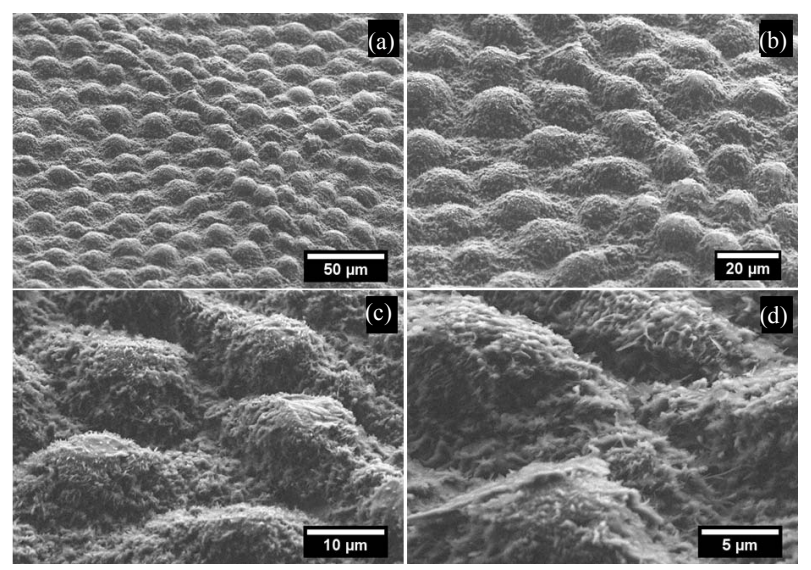

Figure 4. SEM images of the adaxial side of a quaking aspen leaf harvested on August 7, 2011.

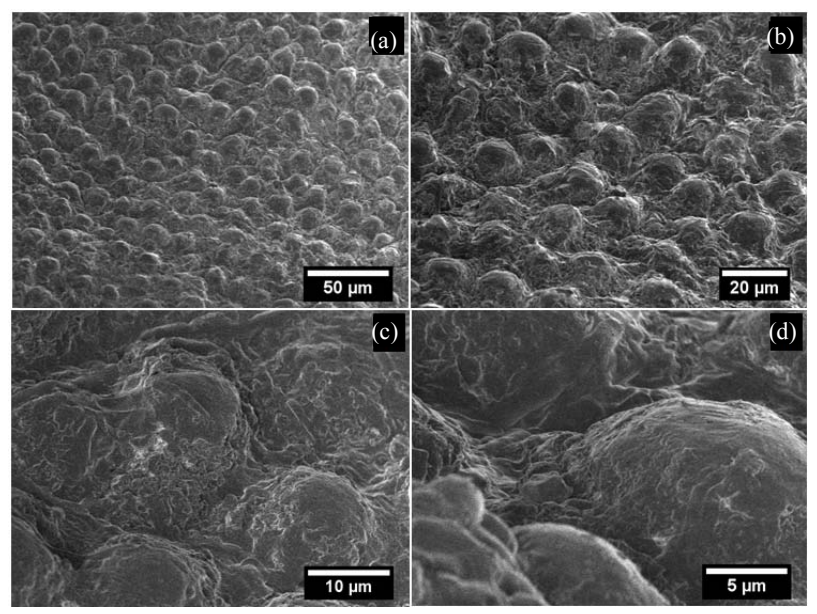

Figure 5. SEM images of the adaxial side of a quaking aspen leaf harvested on September 17, 2011.

finding that is supported by the lack of surface contamination in Figure 2.

Microscopy images from a quaking aspen leaf col- lected on June 5, 2011 are given in Figure 3. Leaves harvested on this date showed micro-scale papillae and nano-scale wax crystals in between them, but most of the wax crystals that covered the papillae tops are no longer present. Nevertheless, leaves gathered on this date still displayed high contact $\left(\sim 160^{\circ}\right)$ and low tilt angles $\left(<5^{\circ}\right)$, suggesting that for good non-wetting properties the presence of wax crystals in between papillae is more crucial than on top of them.

SEM images of a quaking aspen leaf harvested on $\mathrm{Au}-$ gust 7, 2011 are displayed in Figure 4. Leaves obtained at this point in the summer exhibited similar surface features to those collected on May 22 and June 5, 2011. In fact, all leaves gathered between May 22 and August 21 showed similar micro and nano-scale surface features. The leaf imaged in Figure 4 possesses slightly larger micro-papillae and a denser layer of wax crystals compared to Figure 2. Moreover, this leaf appears to have regenerated the nano-scale wax crystals on top of each papilla that were present on leaves collected on May 22 (Figure 2), but absent on leaves gathered on June 5 (Figure 3). Surfaces harvested on August 7, 2011 still demonstrated good non-wetting properties with an average water contact angle of $151^{\circ} \pm 5^{\circ}$ and a tilt angle less than $5^{\circ}$. In summary, all leaf samples harvested between May 22 and August 21, 2011 had similar superhydrophobic surface structures (essentially differing only in the amount of wax crystals on papillae tops) with the associated high contact angles $\left(>150^{\circ}\right)$ and low tilt angles $\left(<5^{\circ}\right)$.

However, the surface structures of leaves (Figure 5) which were collected on September 17, 2011 differ significantly from all other imaged samples. These coarsely degraded surfaces still exhibit micro-papillae (present on all leaf surfaces except those harvested on May 14, 2011), but the finer, nano-scale wax crystals are no longer visible: both in between and on top of papillae. The lack of surface wax crystals on these surfaces reduced their nonwetting property, resulting in average contact angles of only $92^{\circ} \pm 5^{\circ}$. Furthermore, the tilt angles for these surfaces have significantly increased to the point where droplets still adhered to vertically positioned leaf surfaces (i.e. TA $>90^{\circ}$ ). In fact, all samples collected after August 21 did not display wax crystals on or in between papillae indicting that the regeneration process observed during June and July of the 2011 growth season was no longer occurring. For comparison, SEM images (taken at a sample tilt of $0^{\circ}$ ) of a quaking aspen leaf collected at the end of the 2009 growth season (late September) are given in Figure 6. Leaves harvested at this time still displayed a significant amount of nano-scale wax crystals (Figure 6(d)) and were able to retain their superhydrophobic properties throughout the growth season and even after two years of drying. 


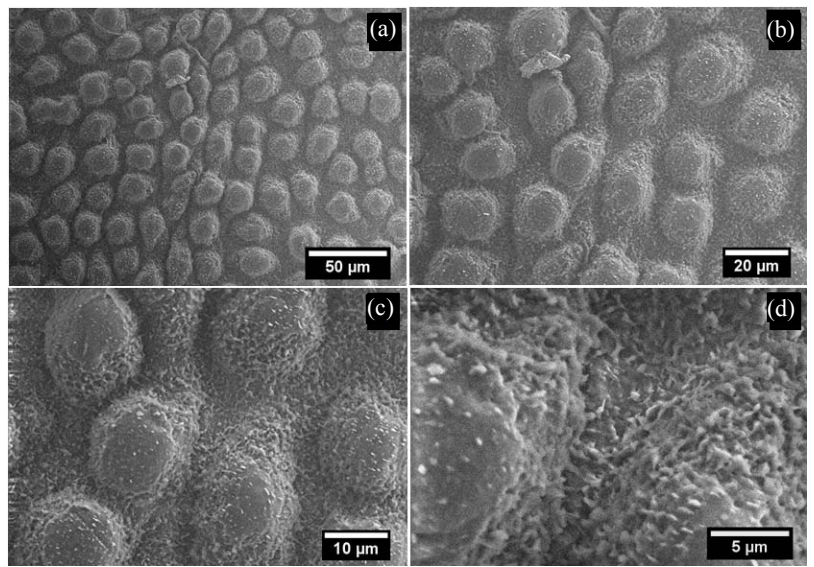

Figure 6. SEM images of the adaxial side of a quaking aspen leaf harvested late in September 2009.

The average contact and tilt angles for all quaking aspen leaves analyzed throughout the summer of 2011 are plotted in Figure 7. This plot can be broken down into 3 distinct regions showing vastly different wetting properties. Leaves obtained the first week after emergence showed only a weak hydrophobic surface property with an average contact angle slightly above $90^{\circ}$ and a relatively large tilt angle of $26^{\circ}$. Just eight days after the first sampling, significant changes in surface structure and wetting properties were observed. The surface structure of the second set of samples had substantially transformed (Figure 2) resulting in much higher contact angles $\left(148^{\circ}\right)$ and much lower tilt angles $\left(<5^{\circ}\right)$. Following this initial change, for most of the summer season until August 21, 2011, aspen leaf contact angles remained high $\left(140^{\circ}-160^{\circ}\right)$ and tilt angles remained low $\left(<5^{\circ}\right)$. During this time the contact and tilt angles fluctuated slightly but for the most part remained close to the superhydrophobic range $\left(\mathrm{CA}>150^{\circ}\right.$ and $\left.\mathrm{TA}<5^{\circ}\right)$. Similar fluctuations in the contact angles throughout the growing season as observed here in region 2 were previously reported for ginkgo (Ginkgo biloba), oak (Quercus robur) and beech (Fagus sylvatica) leaves [18]. These fluctuations could be due to small surface structure differences on the different leaf samples. Another reason could be that leaves collected at different times throughout the year are at different stages in the wax crystal erosion/regeneration cycles. However, after August 21, 2011 the non-wetting property of the quaking aspen leaves was permanently lost resulting in low contact and high tilt angles. Again, it is important to note that leaves harvested from the same tree in previous years (2007-2010) did not show a reduced non-wetting property at the end of past growth seasons [8]. Moreover, leaves from previous years still exhibited extreme non-wetting properties and associated superhydrophobic surface structures after leaf abscission, and even when re-measuring their wetting properties following several years of drying.

\section{Discussion}

It has been previously shown that most leaves can be characterized into four groups based on their ability for wax crystal regeneration: 1) regeneration occurs at all stages of development, 2) regeneration occurs only during leaf expansion, 3) regeneration occurs only in fully developed leaves and 4) plants are not able to regenerate wax crystals at all [19]. This results in some leaves having good non-wetting properties throughout their entire life cycle while others only possess this property in certain stages of growth. It is also commonly accepted that wax crystals are constantly eroded by different environmental factors (wind, precipitation, temperature, etc.) resulting in substantial depletion of the outer most wax layer after prolonged exposure [15]. In all cases the depleted wax layer results in increased leaf wettability and reduced contact angles. Leaves exhibiting dual-scale surface structures (micro-papillae and nano-scale wax crystals) are known to be more resistant to natural wax erosion due to their micro-papillae surface features [19]. Leaves displaying this type of erosion resistant surface structure coupled with the ability to regenerate waxes at all stages of development typically show superhydrophobic properties throughout their entire life cycle. In all four years before 2011, quaking aspen leaves harvested from the same tree/forest fell into this group of leaves. Throughout each season, their wax crystals were constantly being naturally eroded, while simultaneously being regenerated. Perhaps the differences in wax crystal density and wetting properties for leaves collected in 2011 compared to previous years can be explained by considering the environmental factors affecting both wax crystal erosion and regeneration rates. For this analysis all available weather data was taken from Environment Canada's National Climate Data and Information Archive-Peterborough/ Trent University weather station [21]. This particular station is within $20 \mathrm{~km}$ of the quaking aspen tree examined in the current study.

To study the factors affecting wax crystal erosion/regeneration of quaking aspen leaves during the 2011 growth season and a previous year (2009) where superhydrophobicity was observed throughout the entire season, a cumulative environmental effect approach has been employed. The most important environmental factors for wax crystal loss/regeneration are likely temperature, wind gusts and relative humidity (R.H.). In order to assess their relative effects the following analysis considers certain arbitrary thresholds for these factors: wind gusts $>40 \mathrm{~km} / \mathrm{hr}$, temperature $>25^{\circ} \mathrm{C}$ and relative hu- 


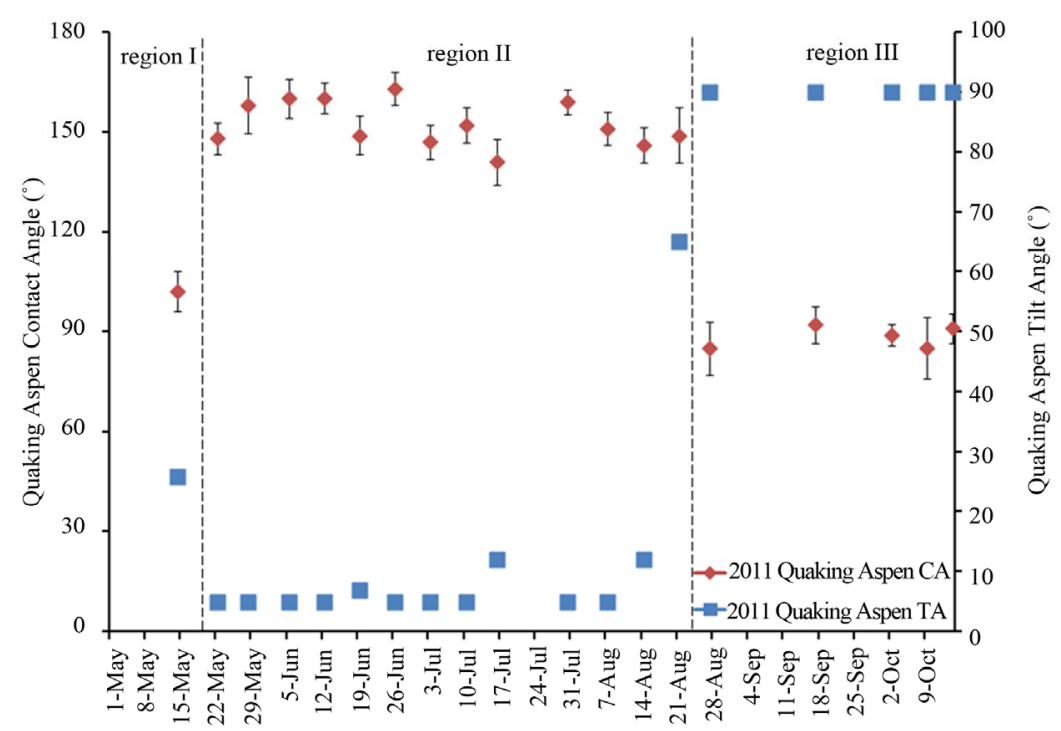

Figure 7. Quaking aspen contact and tilt angles during the 2011 growth season.

midity $>95 \%$. Also considered was cumulative precipitation over the growth period. Using cumulative values for these environmental factors rather than day-by-day data has the advantage that the overall longer term impact on the critical wax crystal erosion/regeneration process is better captured. A single day event analysis was initially attempted, but no clear trends as with the cumulative analysis presented here were observed.

Figure 8 is a plot of the cumulative wind gust events greater than $40 \mathrm{~km} / \mathrm{h}$ for the 2009 and 2011 growth seasons, while Figures 9 and 10, respectively, plot the cumulative precipitation and cumulative hours with temperatures above $25^{\circ} \mathrm{C}$ for the same two years. These figures also contain the contact angles from Figure 7 for quaking aspen leaves gathered on different dates during 2011. For 2009 and 2011 the wind gust and precipitation profiles are quite similar. On the other hand, the cumulative hours above $25^{\circ} \mathrm{C}$ for these two years differ substantially. In 2011, there was more than two and a half times the number of hours with temperatures above $25^{\circ} \mathrm{C}$ compared to 2009. Elevated temperatures have been shown to soften and in certain cases remove/melt leaf wax crystals, resulting in decreased water contact angles $[3,8]$. The elevated temperatures experienced during 2011 undoubtedly resulted in high wax erosion stresses on quaking aspen leaf surfaces. The warmer, softened wax crystals are more susceptible to wind and precipitation erosion.

The exact mechanisms for wax crystal regeneration are not fully understood, but a few possibilities have been proposed. It is widely accepted that for this process to proceed there must be a net movement of wax molecules through the leaf cuticle to the outermost layer. Initially it was thought that microchannels were present that al- lowed the transport of molecules through the cuticle; however a previous study found no such microchannels [22]. In 2001, Neinhuis et al. proposed that wax molecules are co-transported across the cuticle with the continuous current of water molecules flowing through the leaf: a hypothesis that was well supported by their experimental data [19]. This mechanism is further supported by the findings of Baker in 1982 [23]. They observed that wax production (regeneration) rates decreased with increasing relative humidity. If wax molecules do co-transport with water flowing through the cuticle, the amount of wax molecules getting to the leaf's surface will decrease with reduced water flow through the plant. At higher relative humidity levels there will be a lower driving force pushing water through the leaves resulting in reduced transpiration rates, and consequently reduced amounts of wax molecules reaching the outermost layer of the leaves.

Figure 11 shows the cumulative hours above $95 \%$ R.H. for 2009 and 2011, again with the contact angles for quaking aspen leaves harvested during 2011. There is clearly a very large difference in the number of hours with R.H. above $95 \%$ between the two years. There were almost 300 hours where R.H. was above $95 \%$ in 2011 while this value was zero for 2009. It is also interesting to note that around the middle of August 2011, when the quaking aspen leaves' contact angles drastically dropped, the cumulative R.H. increased significantly. Using Neinhuis et al.'s proposed mechanism for wax crystal transport [19], and Baker and Hunt's inverse relationship for R.H. and wax crystal regeneration [15], it appears that the drastic drop in the contact angle for quaking aspen leaves during August of 2011 (which was not observed in 2009) can 


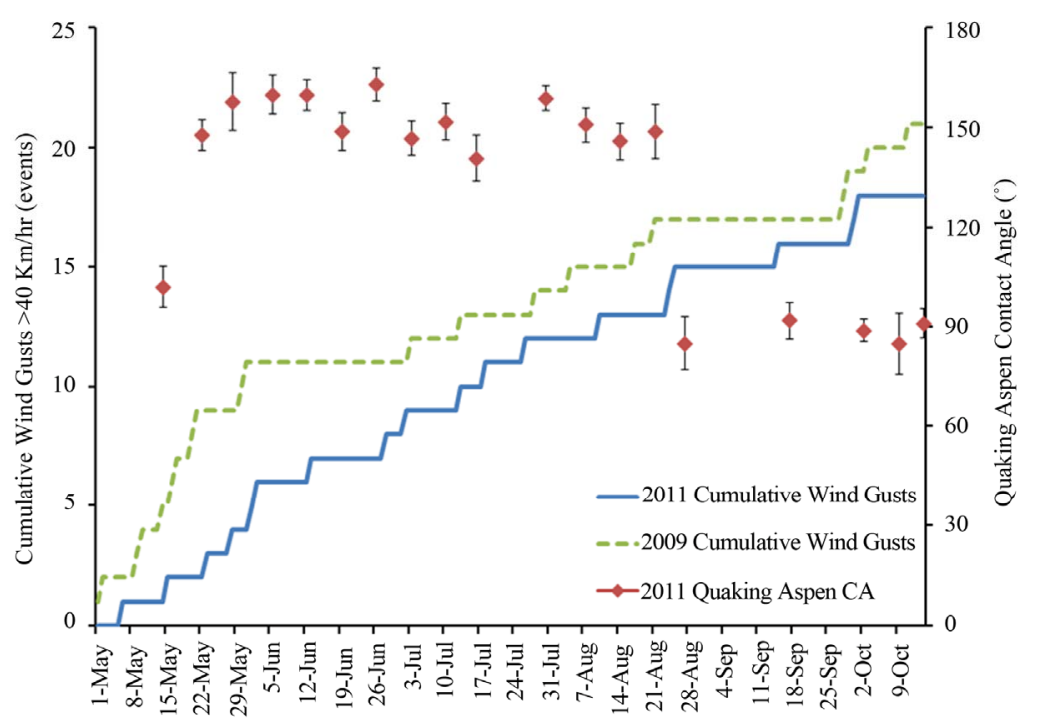

Figure 8. Quaking aspen contact angles and cumulative wind gusts above $40 \mathrm{~km} / \mathrm{h}$ for the growth seasons of 2011 and 2009.

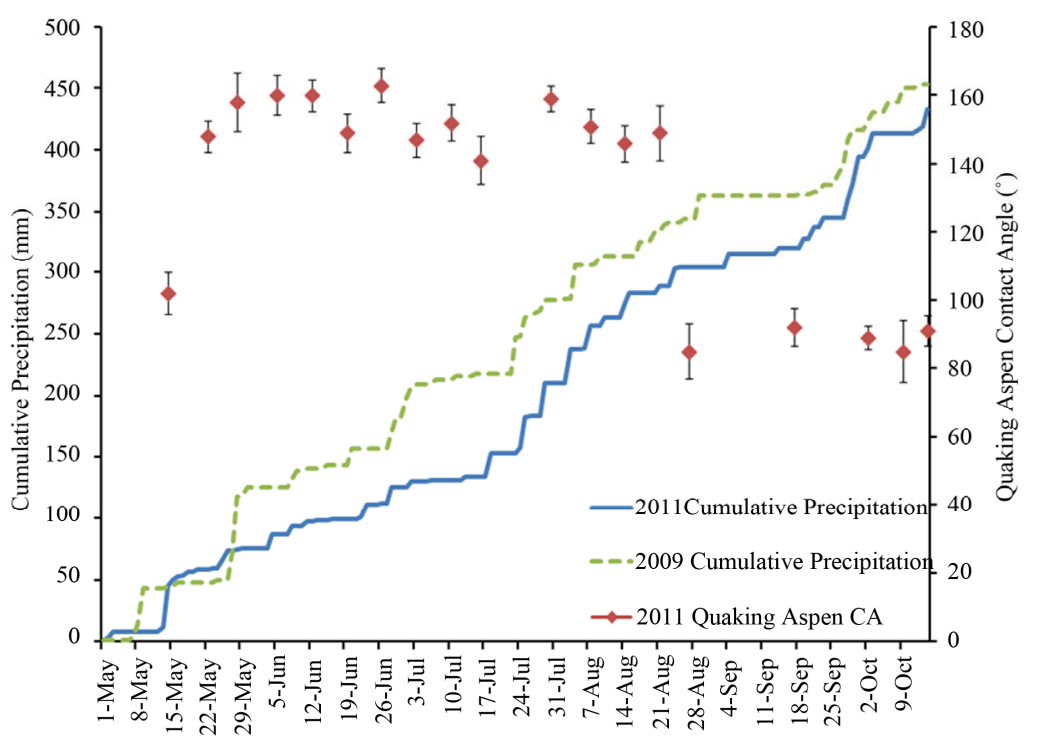

Figure 9. Quaking aspen contact angles and cumulative precipitation for the growth seasons of 2011 and 2009.

be explained, at least in part, by this significant difference in R.H. for 2009 and 2011. Furthermore, a study performed by Koch et al. that monitored the morphology and leaf surface wettability of plants cultivated in different controlled humidity chambers, showed that plants grown at high R.H. exhibited significantly lower amounts of surface wax crystals and reduced contact angles compared to plants cultivated at lower R.H. [16]. All three plant species they studied (brassicaceae, myrtaceae and tropaeolaceae) showed notable decreases in both surface wax crystal density and contact angles when cultivated at very high relative humidity values of $98 \%$ or above. This observation was used to justify the selection of $95 \%$ R.H. as the threshold value in the current study.

It appears that in most years quaking aspen leaves are well suited to withstand the effects of wax crystal erosion through an effective mechanism for wax regeneration. Normally, this allows them to retain their superhydrophobic surface property throughout their entire life cycle. The effect of this continuous erosion and regeneration of wax crystals is illustrated by the fluctuating contact angles observed during the early and middle parts of the 2011 growth season. In unusual weather conditions, like those observed during 2011, wax erosion rates may increase and/or wax regeneration rates may decrease which can result in a less dense layer or complete loss of sur- 


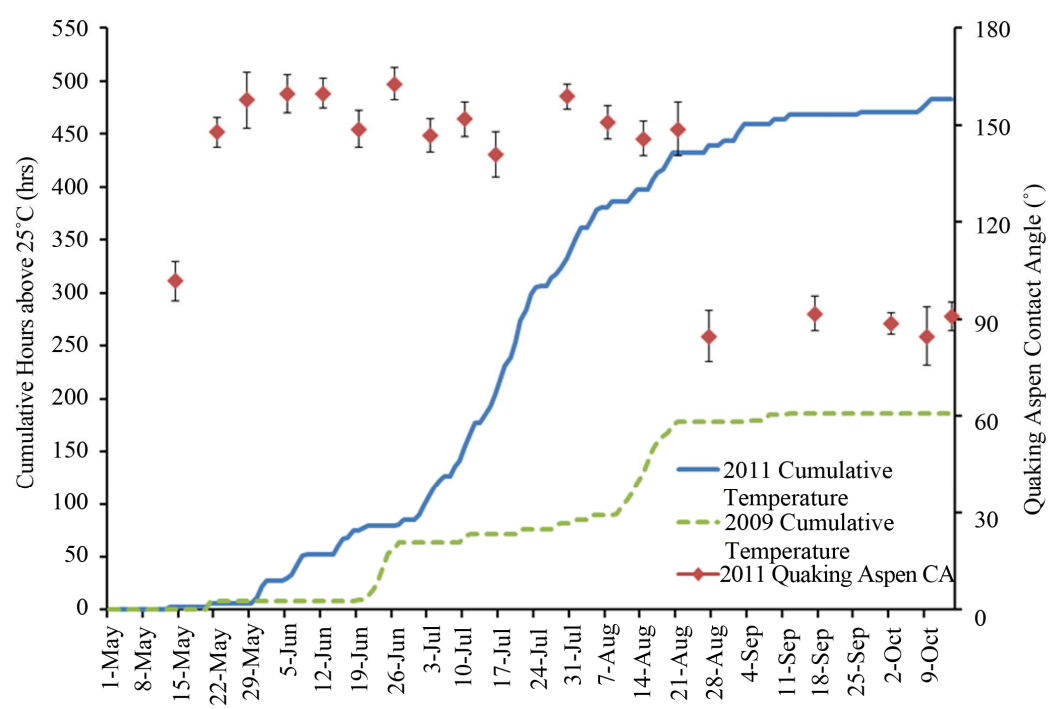

Figure 10. Quaking aspen contact angles and cumulative hours above $25^{\circ} \mathrm{C}$ for the growth seasons of 2011 and 2009.

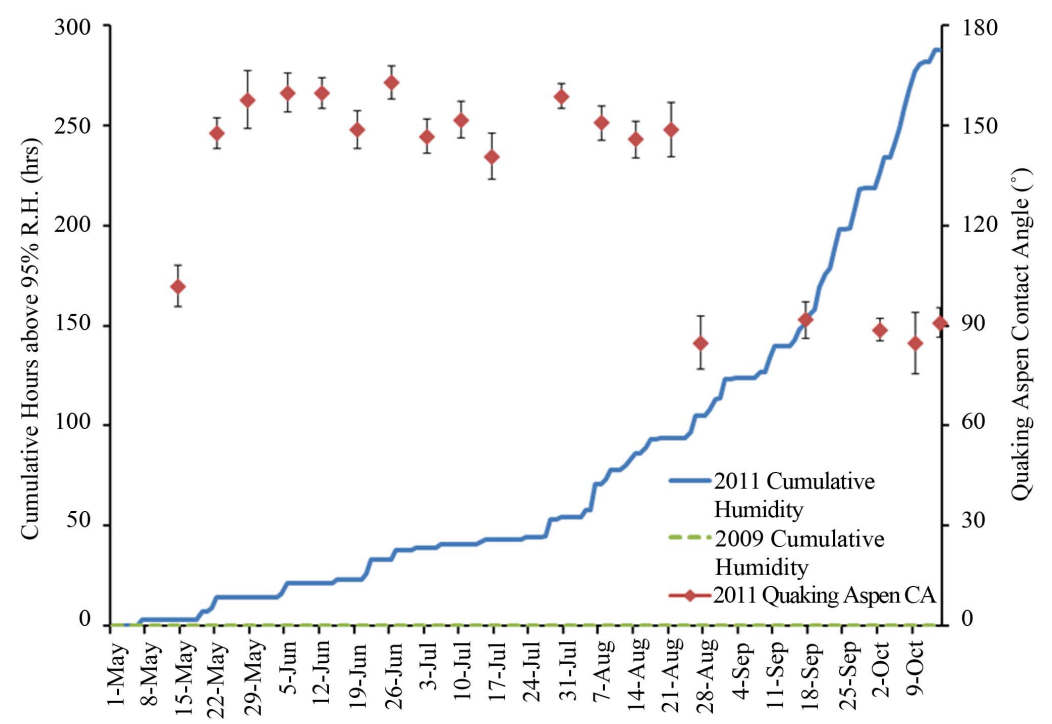

Figure 11. Quaking aspen contact angles and cumulative hours above 95\% R.H. for the growth seasons of 2011 and 2009.

face wax crystals and consequently reduced water contact angles. It should be noted that a considerable, but gradual, reduction of the wetting angle throughout the growth season due to the loss of wax crystals has previously also been reported for oak leaves [5]. However in this study the influences of weather conditions on the wax crystal loss/regeneration were not analyzed.

Finally, the current study did not specifically focus on the initial rapid increase of the wetting angle in the early stages of leaf growth (region I in Figure 7) and the significant changes in leaf surface morphology over a very short period of time, as shown in Figures 1 and 2. This issue will be addressed in a future study with the specific objective to shed more light on the initial growth of the wax crystals.

\section{Conclusion}

In this study, the surface morphology and wetting properties of quaking aspen leaves collected throughout the 2011 growth season were analyzed in order to understand the unexpected loss of superhydrophobicity of these leaves for this particular year. SEM images illustrating structural changes during this growth season are given. Initially, the leaf surfaces show multiple cuticular folds and no nano-scale wax crystals, but within one week of growth they display an array of micro-scale papillae covered by a dense layer of nano-scale wax crystals. Compared to 
previous years, an unexpected reduction in the non-wetting characteristics of these leaves was observed during August 2011 which was correlated to changes in surface morphology, i.e. the loss of leaf surface wax crystals. The possible effects of wind, precipitation, temperature and relative humidity on wax crystal erosion and regeneration rates were analyzed with focus on weather differences between the 2009 and 2011 growth seasons. Using the weather data, it was concluded that the reduction in contact angles and associated morphological changes observed in 2011 were mainly the consequence of an unusually hot and humid year.

\section{REFERENCES}

[1] W. Barthlott and C. Neinhuis, "Purity of the Sacred Lotus Leaf, of Escape from Contamination in Biological Surfaces," Planta, Vol. 202, No. 1, 1997, pp. 1-8. doi:10.1007/s004250050096

[2] B. Bhushan and Y. C. Jung, "Micro- and Nanoscale Characterization of Hydrophobic and Hydrophilic Leaf Surfaces," Nanotechnology, Vol. 17, No. 11, 2006, pp. 27582772. doi:10.1088/0957-4484/17/11/008

[3] Y. T. Cheng, D. E. Rodak, C. A. Wong and C. A. Hayden, "Effects of Micro- and Nano-Structures on the SelfCleaning Behaviour of Lotus Leaves," Nanotechnology, Vol. 17, No. 5, 2006, pp. 1359-1362. doi:10.1088/0957-4484/17/5/032

[4] K. Koch, B. Bhushan and W. Barthlott, "Diversity of Structure, Morphology and Wetting of Plant Surfaces," Soft Matter, Vol. 4, No. 10, 2008, pp. 1943-1963. doi: $10.1039 / \mathrm{b} 804854 \mathrm{a}$

[5] C. Neinhuis and W. Barthlott, "Characterization and Distribution of Water-Repellent, Self-Cleaning Plant Surfaces," Annals of Botany, Vol. 79, No. 6, 1997, pp. 667677. doi:10.1006/anbo.1997.0400

[6] Y. T. Cheng and D. E. Rodak, "Is the Lotus Leaf Superhydrophobic?" Applied Physics Letters, Vol. 86, No. 14, 2005, Article ID: 144101. doi:10.1063/1.1895487

[7] K. Koch, B. Bhushan and W. Barthlott, "Multifunctional Surface Structures of Plants: An Inspiration for Biomimetics," Progress in Materials Science, Vol. 54, No. 2, 2009, pp. 137-178. doi:10.1016/j.pmatsci.2008.07.003

[8] J. J. Victor and U. Erb, "Superhydrophobic Structures on the Basis of Aspen Leaf Design," International Journal of Micro-Nano Scale Transport, Vol. 1, No. 4, 2010, pp. 323-334. doi:10.1260/1759-3093.1.4.323

[9] Z. Burton and B. Bhushan, "Hydrophobicity, Adhesion, and Friction Properties of Nanopatterned Polymers and Scale Dependence for Micro- and Nano-Electromechanical Systems," Nano Letters, Vol. 5, No. 8, 2005, pp. 1607-1613. doi:10.1021/n1050861b

[10] M. Nosonovsky and B. Bhushan, "Biomimetic Superhydrophobic Surfaces: Multiscale Approach," Nano Letters,
Vol. 7, No. 9, 2007, pp. 2633-2637.

doi:10.1021/n1071023f

[11] N. J. Shirtcliffe, G. McHale, M. I. Newton, G. Chabrol and C. C. Perry, "Dual-Scale Roughness Produces Unusually Water-Repellent Surfaces," Advanced Materials, Vol. 16, 2004, pp. 1929-1932. doi:10.1002/adma.200400315

[12] M. Thieme, R. Frenzel, S. Schmidt, F. Simon, A. Hennig, H. Worch, K. Lunkwitz and D. Scharnweber, "Generation of Ultrahydrophobic Properties of Aluminium-A First Step to Self-Cleaning Transparently Coated Metal Surfaces," Advanced Engineering Materials, Vol. 3, No. 9, 2001, pp. 691-695. doi:10.1002/1527-2648(200109)3:9<691::AID-ADEM69 $\underline{1>3.0 . \mathrm{CO} ; 2-8}$

[13] J. J. Victor, D. Facchini, G. Palumbo and U. Erb, "Biology Inspired Superhydrophobic Surfaces," Advanced Materials Research, Vol. 409, 2012, pp. 814-819.

[14] J. J. Victor, D. Facchini and U. Erb, "A Low-Cost Method to Produce Superhydrophobic Polymer Surfaces," Journal of Materials Science, Vol. 47, No. 8, 2012, pp. 3690-3697. doi:10.1007/s10853-011-6217-x

[15] E. A. Baker and G. M. Hunt, "Erosion of Waxes from Leaf Surfaces by Simulated Rain," New Phytologist, Vol. 102, No. 1, 1986, pp. 161-173. doi:10.1111/j.1469-8137.1986.tb00807.x

[16] K. Koch, A. Dommisse and W. Barthlott, "Chemistry and Crystal Growth of Plant Wax Tubules of Lotus (Nelumbonucifera) and Nasturtium (Tropaeolummajus) Leaves on Technical Substrates," Crystal Growth and Design, Vol. 6, 2006, pp. 2571-2578. doi:10.1021/cg060035w

[17] K. Koch, K. D. Hartmann, L. Schreiber, W. Barthlott and C. Neinhuis, "Influences of Air Humidity During the Cultivation of Plants on Wax Chemical Composition, Morphology and Leaf Surface Wettability," Environmental and Experimental Botany, Vol. 56, 2006, pp. 1-9. doi:10.1016/j.envexpbot.2004.09.013

[18] C. Neinhuis and W. Barthlott, "Seasonal Changes of Leaf Surface Contamination in Beech, Oak, and Ginkgo in Relation to Leaf Micromorphology and Wettability," New Phytologist, Vol. 138, No. 1, 1998, pp. 91-98. doi:10.1046/j.1469-8137.1998.00882.x

[19] C. Neinhuis, K. Koch and W. Barthlott, "Movement and Regeneration of Epicuticular Waxes through Plant Cuticles," Planta, Vol. 213, No. 3, 2001, pp. 427-434. doi: $10.1007 / \mathrm{s} 004250100530$

[20] ImageJ, 2007. http://rsbweb.nih.gov/ij/

[21] Weather Data, 2011. http://www.climate.weatheroffice.gc.ca/climateData/cana da e.html

[22] C. E. Jeffree, "Plant Cuticles an Integrated Functional Approach," Bios Scientific, Oxford, 1996.

[23] E. A. Baker, "The Plant Cuticle," Academic Press, London, 1982. 